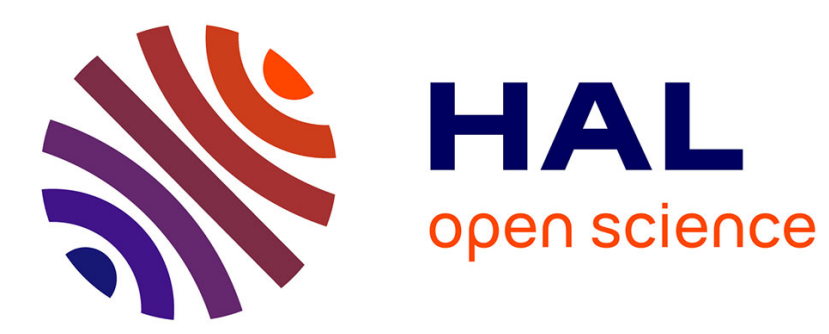

\title{
Reduced graphene oxide--silsesquioxane hybrid as a novel supercapacitor electrode
}

Wlodzimierz Czepa, Samanta Witomska, Artur Ciesielski, Paolo Samori

\section{To cite this version:}

Wlodzimierz Czepa, Samanta Witomska, Artur Ciesielski, Paolo Samori. Reduced graphene oxidesilsesquioxane hybrid as a novel supercapacitor electrode. Nanoscale, 2020, 12 (36), pp.18733-18741. 10.1039/D0NR05226D . hal-02959579

\section{HAL Id: hal-02959579 https://hal.science/hal-02959579}

Submitted on 6 Oct 2020

HAL is a multi-disciplinary open access archive for the deposit and dissemination of scientific research documents, whether they are published or not. The documents may come from teaching and research institutions in France or abroad, or from public or private research centers.
L'archive ouverte pluridisciplinaire HAL, est destinée au dépôt et à la diffusion de documents scientifiques de niveau recherche, publiés ou non, émanant des établissements d'enseignement et de recherche français ou étrangers, des laboratoires publics ou privés. 


\title{
ARTICLE
}

\section{Reduced graphene oxide - silsesquioxane hybrid as novel supercapacitor electrode}

Received 00th January 20xx, Accepted 00th January 20xx

DOI: $10.1039 / x 0 \times x 00000 x$

\author{
Włodzimierz Czepa, ${ }^{\text {ab }}$ Samanta Witomska, ${ }^{\text {ab }}$ Artur Ciesielski ${ }^{* b c}$ and Paolo Paolo Samori ${ }^{* c}$
}

Supercapacitor energy storage devices recently garnered considerable attention due to their cost-effectiveness, eco-friendly nature, high power density, moderate energy density and long-term cycle stability. Such figures of merit render supercapacitors unique energy sources to power portable electronic devices. Among various energy storage materials, graphene-related materials have established themselves as ideal electrodes for the development of elite supercapacitors because of their excellent electrical conductivity, high surface area, outstanding mechanical properties combined with the possibility to tailor various physical and chemical properties via chemical functionalization. Increasing the surface area is a powerful strategy to improve the performance of supercapacitors. Here, modified polyhedral oligosilsesquioxane (POSS) is used to improve electrochemical performance of reduced graphene oxide $(\mathrm{rGO})$ through the enhancement of porosity and the extension of interlayer space between the sheets allowing the efficient electrolyte transport. rGO-POSS hybrids exhibited high specific capacitance of $174 \mathrm{~F} \mathrm{~g}^{-1}$, power density reaching $2.25 \mathrm{~W} \mathrm{~cm}^{-3}$ and high energy density of $41.4 \mathrm{mWh}_{\mathrm{cm}}^{-3}$ endowed by the introduction of POSS-spacer. Moreover, these electrode materials display excellent durability reaching $>98 \%$ retention after 5000 cycles.

\section{Introduction}

The ever-increasing energy demand has triggered an intensive search for sustainable and renewable power sources which have led to the emergence of multiple technological solutions including clean energy conversion and storage devices. In fact, the nowadays most employed energy sources such as fossil fuels, coal, oil and natural gasses are neither ecofriendly nor everlasting. Fossil fuel burning releases harmful gasses, resulting in continues deterioration of the global environment. During the last decades, renewable energy sources has become extremely important because of their sustainability and efficiency combined with their pollution-free processability. Among them, supercapacitors (SCs) have received considerable attention as modern portable energy storage devices featuring high power density, ultrafast charge-discharge, long cycle life, high operating durability and low maintenance. ${ }^{1,2}$ Since the first demonstration of SC in 1957 by Becker using porous carbon electrodes, much progress has been made in this research area. Albeit a vast number of electrode materials have been reported so far, carbon nanomaterials attracted greatest attention due to their unique physicochemical and electrochemical

\footnotetext{
a. Faculty of Chemistry, Adam Mickiewicz University Uniwersytetu Poznańskiego 8, 61614 Poznań, Poland

b. Center for Advanced Technologies, Adam Mickiewicz University, Uniwersytetu Poznańskiego 10, 61614 Poznań, Poland

c. Université de Strasbourg, CNRS, ISIS, 8 alleé Gaspard Monge, 67000 Strasbourg, France

Electronic Supplementary Information (ESI) available: [SEM/EDX picture, FT-IR spectra, XRD patterns, BET isotherms, charge-discharge curves, stability investigations and comparison of $\mathrm{rGO}$ based electrodes properties]. See DOI: $10.1039 / x 0 x \times 00000 x$
}

properties. In particular, the use of graphitic carbon nanomaterials yielded an increase in the overall performance of SCs. Moreover carbonaceous electrodes represent an ecological friendly alternative for traditional energy storage devices such as batteries. ${ }^{3,4}$ Considering the mechanism of charge storage, supercapacitors can be classified as electrical double layer capacitors (EDLCS) based on electrostatic adsorption of electrolyte ions onto the surface of electrodes and pseudocapacitors (PCs) additionally supported by Faradaic redox reactions. Notably, EDLCs are beneficial especially in terms of higher power density and longer cyclic stability but they exhibit lower power density than PCs. ${ }^{5,6}$

Among all carbon-related materials which can be used as electrode for EDLCs, graphene possesses the largest surface area (up to $2700 \mathrm{~m}^{2} / \mathrm{g}$ ). However, graphene-based supercapacitors exhibit significant quasi-rectangular curves at lower scan rates (1-10 $\left.\mathrm{mV} \mathrm{s}^{-1}\right)$ due its densely packed layered structure, kinetically limiting electrolyte ions penetration at higher scan rates thereby resulting in overall electrochemical performance decrease. ${ }^{7}$

Three-dimensional (3D) graphene-based architectures have allured remarkable attention for EDLCs applications owing to their highly accessible surface area, low density, structural interconnectivity (micro-, meso- and macro-interconnected pores), excellent electrical conductivity and good mechanical features. Overall, supercapacitance performance of 3D graphene-based SC has been correlated to the enhanced accessibility of the electrode surface to electrolyte ions, which also provides conductive channels for electron transfer. Such an increase of the dimensionality can be beneficial in terms of physicochemical properties of hybrid materials. ${ }^{8-10}$ Therefore, 
the use of porous scaffolds can be an asset especially in terms of specific surface area, presence of the pores with controllable size and effective charge transport.

Graphene-based materials, which are notorious because of their exceptional electrical and mechanical properties, can be produced either via bottom-up or top-down strategies.11-14 Among the various GRMs, graphene oxide (GO) offers multiple advantageous features including a good dispersibility in aqueous media and an easy chemical functionalization. ${ }^{15}, 16$ Notably, GO exhibits modest electrical properties compared to pristine graphene due to existence of multiple structural defects in the $\mathrm{sp}^{2}$ lattice combined by the presence of various oxygen containing groups. ${ }^{17,18}$ However, GO can be reduced leading to reduced graphene oxide ( $\mathrm{rGO}$ ). The latter, which can have a sheet resistance of a few $\Omega / \square$, can be efficiently used as electrode in different device types. ${ }^{19}$ In a simplistic model, the conductivity of graphene-based materials is proportional to the carbon to oxygen ratio. However, other parameters such as geometrical aspects, including sheets orientation and percolation effects, play also a non-negligible role. ${ }^{20-22} \mathrm{~A}$ plethora of reduction pathways to restore to a great extent the $\pi$-conjugated electronic structure were proposed and widely applied, including chemical, thermal, electrochemical and microwave-assisted processes. ${ }^{20}, 23-26$ Reduction is a viable approach to generate large quantities of high quality rGO with moderate oxygen content, while the use of structural scaffolding might support electrochemical processes that require effective ions penetratrion. ${ }^{27}$ Chemically reduced GO was previously investigated as a neat component in energy storage applications reaching moderate capacitance ranging from 67 to $100 \mathrm{~F} \mathrm{~g} \mathrm{~g}^{-1}$ mainly due to limited accessibility for electrolyte molecules. The more effective rGO-based electrodes usually exhibit lower cyclability and durability while tested in aqueous media or even require the use of organic electrolytes. ${ }^{28,29}$

Notably, chemically or thermally rGO sheets (or graphene sheets), which combine high electrical conductivity and electrochemical stability, is unfortunately prone to undergo a substantial restacking of graphene sheets when producing macroscopic assemblies from a liquid suspension. This restacking reduces drastically the material's surface area leading to dramatically decreases energy density of the graphene film-based supercapacitor. Therefore, the inhibition of restacking of graphene sheets can be provided by the use of molecular spacers towards to guarantee high specific surface porosity which is required for effective electrolyte penetration. ${ }^{30} \mathrm{~A}$ vast number of approaches using covalent and non-covalent functionalization of graphene-based materials has been explored leading to superior electrochemical performance. ${ }^{31-33}$ It was demonstrated that the appropriate selection of functional molecules allows fine-tuning the interlaminar distance between $\mathrm{rGO}$ sheets and might result in higher capacitance and improved durability of electrodes. ${ }^{34}$ Polyhedral oligomeric silsesquioxanes (POSSs) are inorganic molecules comprising a Si-O cage-like core surrounded by organic sites exposing functional groups. ${ }^{35}$ By exploiting their well-defined structure, high stability and good solubility, POSSs have been employed as attractive functional building block to develop nanohybrid materials, in particular when combined with porous carbon structures. ${ }^{36}, 37$ The introduction of silsesquioxane makes it possible to endow to materials an enhanced durability, rigidity and higher specific surface area. Moreover, the presence of POSS can enhance electrochemical performance of graphene-based materials due to pseudocapatitative co-contribution and expansion of the interlayer space of tightly packed nanosheets.

Here, we report the modification of GO with OctaAmmoniumPOSS followed by chemical reduction of the hybrid to generate rGO-POSS electrodes for supercapacitors. The latter device exhibited enhanced specific capacitance of $173 \mathrm{~F} \mathrm{~g}^{-1}$ thus comparable to the state-of-the-art of chemically $\mathrm{rGO}$ materials. The introduction of POSS resulted in porous structure with specific surface area of $180 \mathrm{~m}^{2} \mathrm{~g}^{-1}$, moderate pores size of $4 \mathrm{~nm}$ allowing effective electrolyte penetration thereby ensuring effective electrochemical performance and exceptional cyclability. The prepared electrodes exhibited high durability and excellent capacitance retention (>98\%) after 5000 cycles. Moreover, the use of molecular spacer provided a high volumetric energy density of $41.4 \mathrm{mWh} \mathrm{cm}^{-3}$. These results provide clear evidence on the beneficial role of POSS in improving the electrochemical performance via simple chemical functionalization of rGO.

\section{Results and discussion}

\subsection{Synthesis and characterization}

The synthesis of rGO-POSS was performed by employing the condensation reaction between primary amine moieties, which are generated upon hydrolysis of ammonium chlorides on the termini of octaammonium POSS and epoxides present on GO surface, mainly via nucleophilic ring opening reaction yielding covalent cross-link of the two components (Fig. 1). Subsequently, the isolated product was chemically reduced with hydrazine to get rid of the excess of oxygen species and non-covalently attached POSS molecules.

Scanning Electron Microscopy (SEM) and Energy-dispersive Xray spectroscopy (EDS) analysis made it possible to gain insight into the morphology and elemental distribution in the final material. Fig. 2a reveals that rGO-POSS possesses a folded structure typical of graphene oxide based hybrids. ${ }^{38-40}$ Elemental mapping confirms the homogenous distribution of the elements in the final material i.e. silicon atoms dispersed in the matrix of $\mathrm{rGO}$, thereby excluding the formation of aggregates (Fig. S1). High-resolution transmission electron microscopy (HR-TEM) was performed to reveal porosity provided by evenly spread POSS cages in the matrix of reduced graphene oxide (Fig. 2b). The estimated average POSS loading amounts to 1 POSS each $10 \mathrm{~nm}^{2}$. Fourier transform infrared 


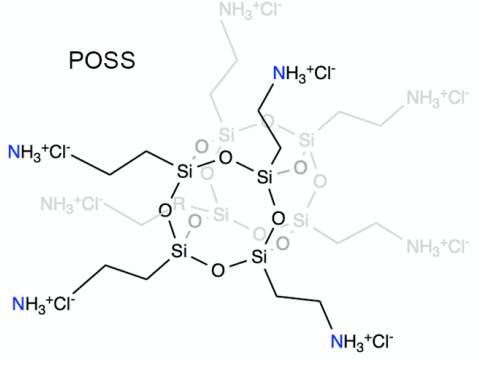

$\mathrm{R}-\mathrm{NH}_{3}{ }^{+} \mathrm{Cl} \stackrel{\text { hydrolyses }}{\longrightarrow} \mathrm{RNH}_{2}+\mathrm{H}_{2} \mathrm{O}+\mathrm{HCl}$

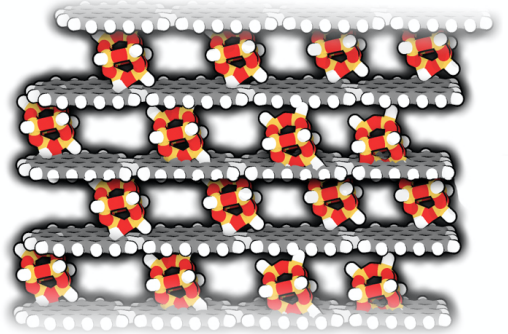

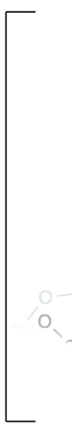
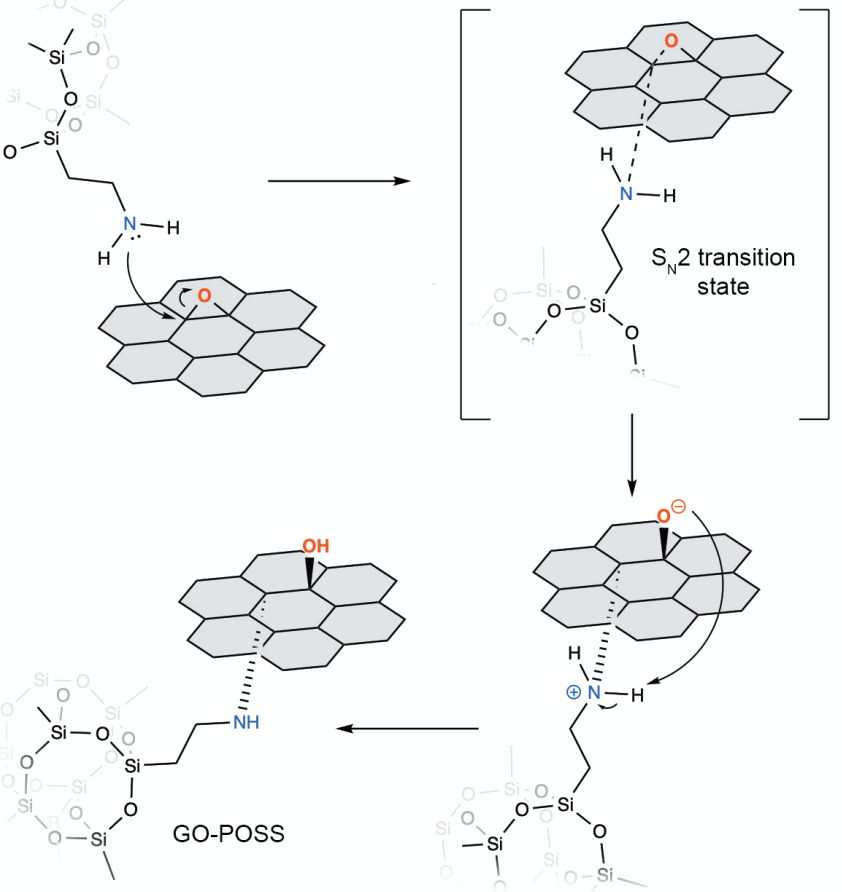

Fig. 1 Scheme representing the mechanism of functionalization of GO with octaammonium POSS.

spectroscopy (FT-IR) spectra of GO, POSS, GO-POSS and rGOPOSS portrayed in Fig. S2 provide evidences for the covalent functionalization of $\mathrm{rGO}$ with POSS. The spectra of pristine GO displays typical peaks associated with $\mathrm{C}=\mathrm{O}$ stretching at 1724 $\mathrm{cm}^{-1}, \mathrm{C}=\mathrm{C}$ stretching at $1624 \mathrm{~cm}^{-1}, \mathrm{C}-\mathrm{O}$ stretching of epoxy groups at 1216 and $1054 \mathrm{~cm}^{-1}$, and a broad peak between 3000 and $3500 \mathrm{~cm}^{-1}$ corresponding to hydroxyl species stretching. The functionalization with POSS molecules determined the appearance of a strong absorption at $1573 \mathrm{~cm}^{-1}$ corresponding to $\mathrm{N}-\mathrm{H}$ stretching vibration, and a broad peak at $3276 \mathrm{~cm}^{-1}$ corresponding to $\mathrm{N}-\mathrm{H}$ vibration for secondary amines suggesting that most of the $-\mathrm{NH}_{2}$ groups took part in covalent bonding to the surface of graphene oxide. ${ }^{41}$ Moreover due to hydrazine reduction we can observe significant decrease of hydroxyl species around $3500 \mathrm{~cm}^{-1}$. Notably, the decreased intensity of peaks corresponding to $\mathrm{C}-\mathrm{O}$ bonds results from functionalization and chemical reduction of final material and was previously reported while cross-linking of GO with aminebased functional molecules. ${ }^{42,} 43$ In addition, the asymmetric peaks at 2937 and $2870 \mathrm{~cm}^{-1}$ are assigned to the $\mathrm{C}-\mathrm{H}$ stretching vibrations of the alkyl group $-\mathrm{CH}_{2}$. The formation of the $\mathrm{rGO}$ POSS composite was further evidenced by the appearance of bands characteristic for siloxane groups i.e. Si-O-Si $\left(1130 \mathrm{~cm}^{-1}\right)$ and $\mathrm{Si}-\mathrm{C}\left(908 \mathrm{~cm}^{-1}\right)$ coming form the core of POSS cage.

X-ray photoelectron spectroscopy (XPS) was exploited to bestow information on the chemical composition of materials
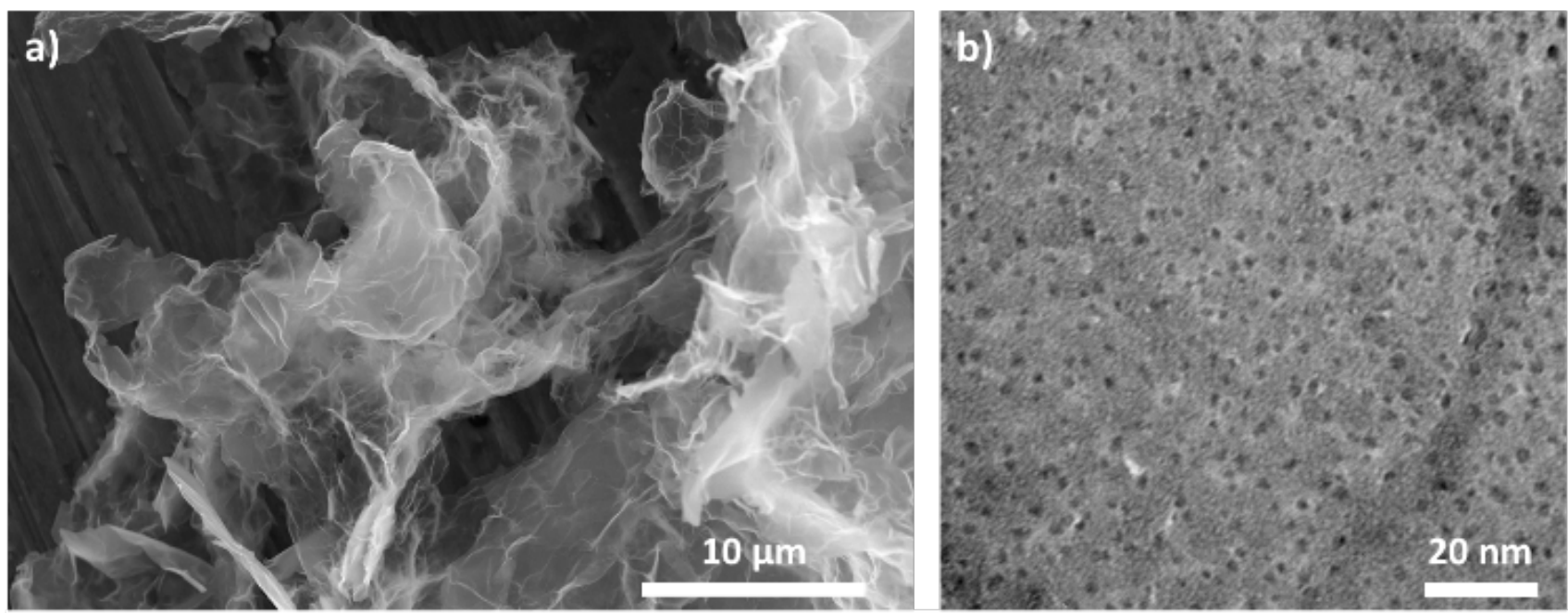

Fig. 2 a) SEM picture of rGO-POSS, b) HR-TEM investigations of rGO-POSS hybrid material. 

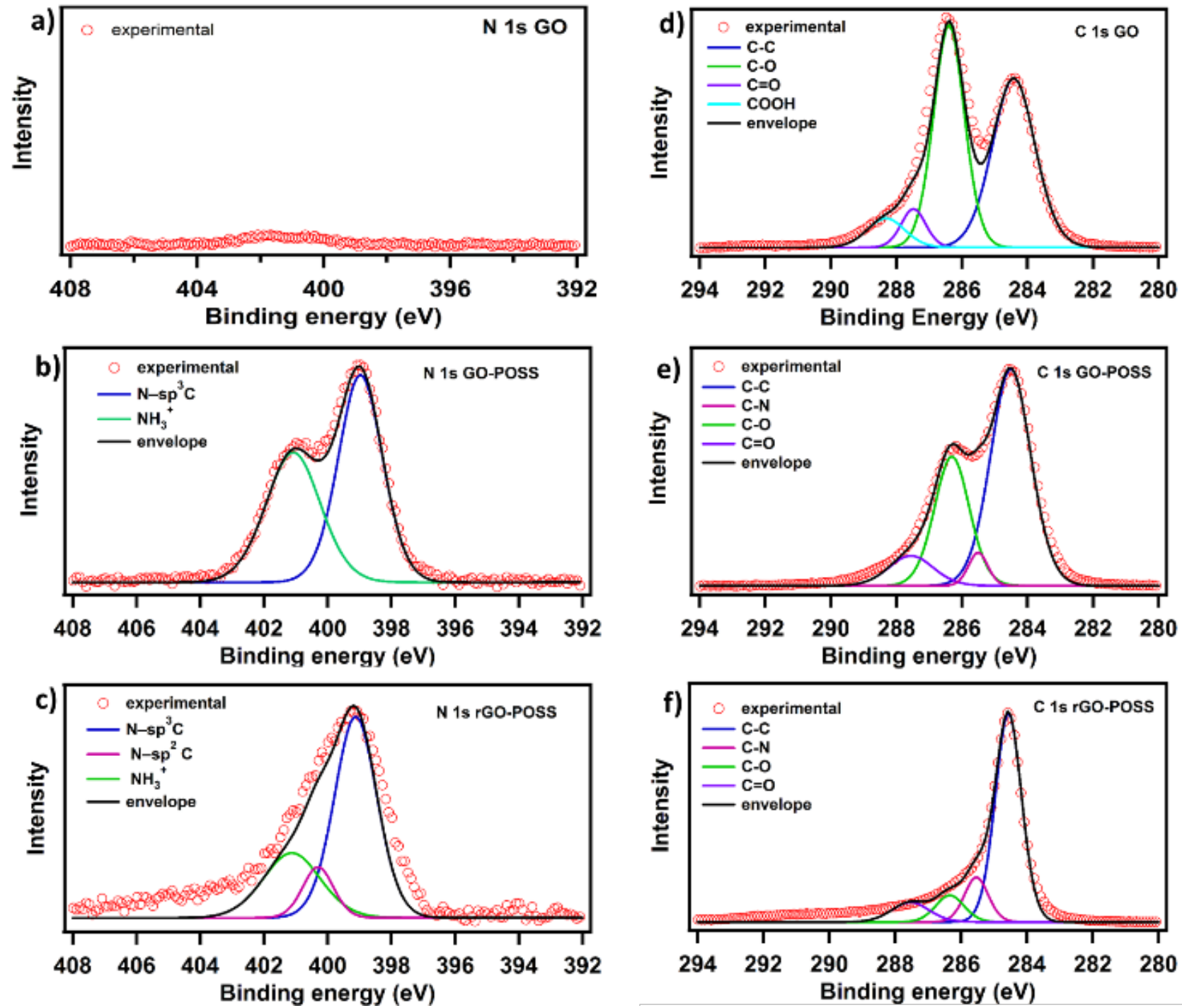

Fig. 3 Comparison of XPS high resolution C1s and N1s spectra for (a,d) GO, (b,e) GO-POSS, and (c,f) rGO-POSS.

by identifying the relevant chemical elements and bonds present in the neat and functionalized GO (see Fig. 3). The C1s spectra of $\mathrm{GO}$ shows peaks corresponding to the $\mathrm{C}-\mathrm{C}(284.6 \mathrm{eV})$, $\mathrm{C}-\mathrm{O}(286.4 \mathrm{eV}), \mathrm{C}=\mathrm{O}(287.5 \mathrm{eV})$ and $\mathrm{COOH}(288.3 \mathrm{eV})$ bonds. Comparably the C1s spectra of the functionalized GO-POSS appears differently and feature peaks at $284.6 \mathrm{eV}, 285.5 \mathrm{eV}$, $286.4 \mathrm{eV}, 287.5 \mathrm{eV}$, which can be assigned to C-C, C-N, C-O and $\mathrm{C}=\mathrm{O}$ bonds, respectively. On the other hand, the $\mathrm{C} 1 \mathrm{~s}$ spectra of rGO-POSS exhibits a significant decrease of $\mathrm{C}-\mathrm{O}$ bonds indicating the successful reduction of unreacted oxygen group on the surface of GO-POSS (Fig. 3c). As expected, the high-resolution N1s spectra of GO sample does not show presence of nitrogen signal. Conversely, signals observed in GO-POSS sample can be deconvoluted into two peaks, i.e. at $398.9 \mathrm{eV}$ and $401.2 \mathrm{eV}$, which can be attributed to secondary ( $\mathrm{N}-\mathrm{sp}^{3}$ bonds) and protonated primary amines, respectively. ${ }^{27}$ Notably, the existence of the external $-\mathrm{NH}_{3}{ }^{+}$groups suggests that only majority of amines undergo the covalent grafting onto $\mathrm{GO}$ sheets with coexistence of electrostatic interactions mostly at the edges of GO surface and form the ammonium-carboxylate species. Interestingly, the non-covalent grafted molecules were easily removed from the GO-POSS during the reduction step which was previously reported in case of functionalization and reduction of graphene based materials. ${ }^{44}$ Moreover the $\mathrm{N}$ 1s spectra of rGO-POSS reveals the decrease of signal corresponding to protonated primary amines (401.2 eV). Additionally, new peak at $400.2 \mathrm{eV}$ on N1s spectra of GO-POSS after hydrazine treatment indicating minor nitrogen inclusion mostly on the edges of $\mathrm{GO}$ sheets forming $\mathrm{N}$-sp ${ }^{2}$ species. ${ }^{45}$ Furthermore, determination of $\mathrm{C} / \mathrm{N}$ ratio, which amounts to 10.2 and 25.4 for GO-POSS and rGO-POSS, respectively, confirm the removal of non-covalently attached POSS molecules. ${ }^{44}$

Thermogravimetric analysis was performed to investigate thermal stability and composition of GO, POSS and RGO-POSS. The GO curve displays about $45 \%$ weight loss in the range of $150-300^{\circ} \mathrm{C}$ due to oxygen functional groups degradation. POSS exhibits good thermal stability up to $340^{\circ}$ when organic aminopropyl- species start to decompose and with the 
temperature increase lading to formation of amorphous $\mathrm{SiO}_{2} \cdot{ }^{46}$ 47 The rGO-POSS curve show similar mass drops corresponding to organic functional groups degradation with the $20 \%$ mass residue coming from the POSS Si-O core.

Powder X-ray diffraction investigations were performed to study the POSS intercalation into 3D structure and structural orientation changes due to the functionalization. Wide-angle Xray scattering (WAXS) of the pristine GO displays only a typical sharp peak at $\approx 10.01^{\circ}$ (see Figure S3), corresponding to an interlayer spacing of $0.87 \mathrm{~nm}$ due to the (002) reflection of stacked GO sheets, in accordance with the previously reported value.48, 49 Interestingly after functionalization with POSS, significant shift of the peak towards lower angle values $\left(7.65^{\circ}\right)$ has been observed, the latter corresponding to an increased interlayer spacing of $1.15 \mathrm{~nm}$. The latter can be assigned to intercalation of POSS particles with sizes of ca. $0.5 \mathrm{~nm}$ (core shell) which vary depending on the substituents. ${ }^{50}$ Moreover, due to functionalization new broad peak at $21.03^{\circ}$ coming from POSS is observed. After reduction with hydrazine, a new peak at $27.96^{\circ}$ appears suggesting the presence of new crystalline domains, which corresponds to partially restored graphitic domains and $\pi-\pi$ interactions with significant shift comparing to rGO resulted from the presence of POSS species. ${ }^{44}$ Moreover chemical reduction provides removal of non-covalently attached POSS cages in accordance with XPS results. The irregular intercalation of POSS between graphene sheets results in broadening of peak towards $2 \theta$ range of $6-11^{\circ}$ and broad signals around $20^{\circ}$ and $30^{\circ}$ corresponding with high intensity peaks of crystalline POSS itself (Fig. S4).

Further insight into the morphologies of rGO-POSS were obtained by quantifying the specific surface area (SSA), pore size and pores distribution with the Brunauer-Emmett-Teller (BET) model which relies on the $\mathrm{N}_{2}$ adsorption desorption. Our hybrid material exhibited large SSA reaching $180 \mathrm{~m}^{2} \mathrm{~g}^{-1}$, which is roughly twice the accessible surface area of pristine GO (Fig. S5). Notably, the material was finally reduced, a reaction which typically is accompanied with a decrease in the surface area. However, in our case, the presence of mesopores during the functionalization made it possible to maintain the porous structure. The IV type hysteresis loop (Fig. S5b) confirms the presence of capillary condensation occurring in mesopores with the new types of pores with the size of $4 \mathrm{~nm}$ and average pore volume of $0.54 \mathrm{~cm}^{3} \mathrm{~g}^{-1}$, which clearly differ morphologically from the materials used for the synthesis (Tab. S1), enabling the effective electrolyte transport during the electrochemical measurements. ${ }^{51-53}$

\subsection{Electrochemical study}

Cyclic voltammetry (CV) was employed to probe the electrochemical behaviour of rGO-POSS electrode in aqueous $\mathrm{H}_{2} \mathrm{SO}_{4}(1 \mathrm{M})$ electrolyte at potential window from 0 to $1 \mathrm{~V}$. The working electrode was investigated at scan rates ranging from $1 \mathrm{mV} \mathrm{s}^{-1}$ to $1000 \mathrm{mV} \mathrm{s}^{-1}$ as shown on Fig. 4. At lower scan rate values (1-100 $\mathrm{mV} \mathrm{s}^{-1}$ ) CV curves display quasi-rectangular shape confirming effective electrolyte ions transport resulting in good electrochemical performance. This phenomena can be assigned to the presence of stable porous structure provided by POSS scaffolding and allows to achieve effective capacitance at higher scan rates, which usually drastically drops over $20 \mathrm{mV} \mathrm{s}^{-1}$ for graphene-based materials. ${ }^{54,55}$ Specific capacitance of $179 \mathrm{~F} \mathrm{~g}^{-1}$ was obtained at scan rate of $1 \mathrm{mV} \mathrm{s}^{-1}$ and represents relatively high result considering chemically reduced graphene oxidebased materials, including the reference hydrazine-reduced graphene oxide reaching $94 \mathrm{~F} \mathrm{~g}^{-1}$ (Fig. S. 10). Additionally, voltamperograms recorded at low scan rates revealed peaks around $0.4 \mathrm{~V}$ suggesting slight co-participation of pseudocapacitance in electrochemical behaviour of electrode
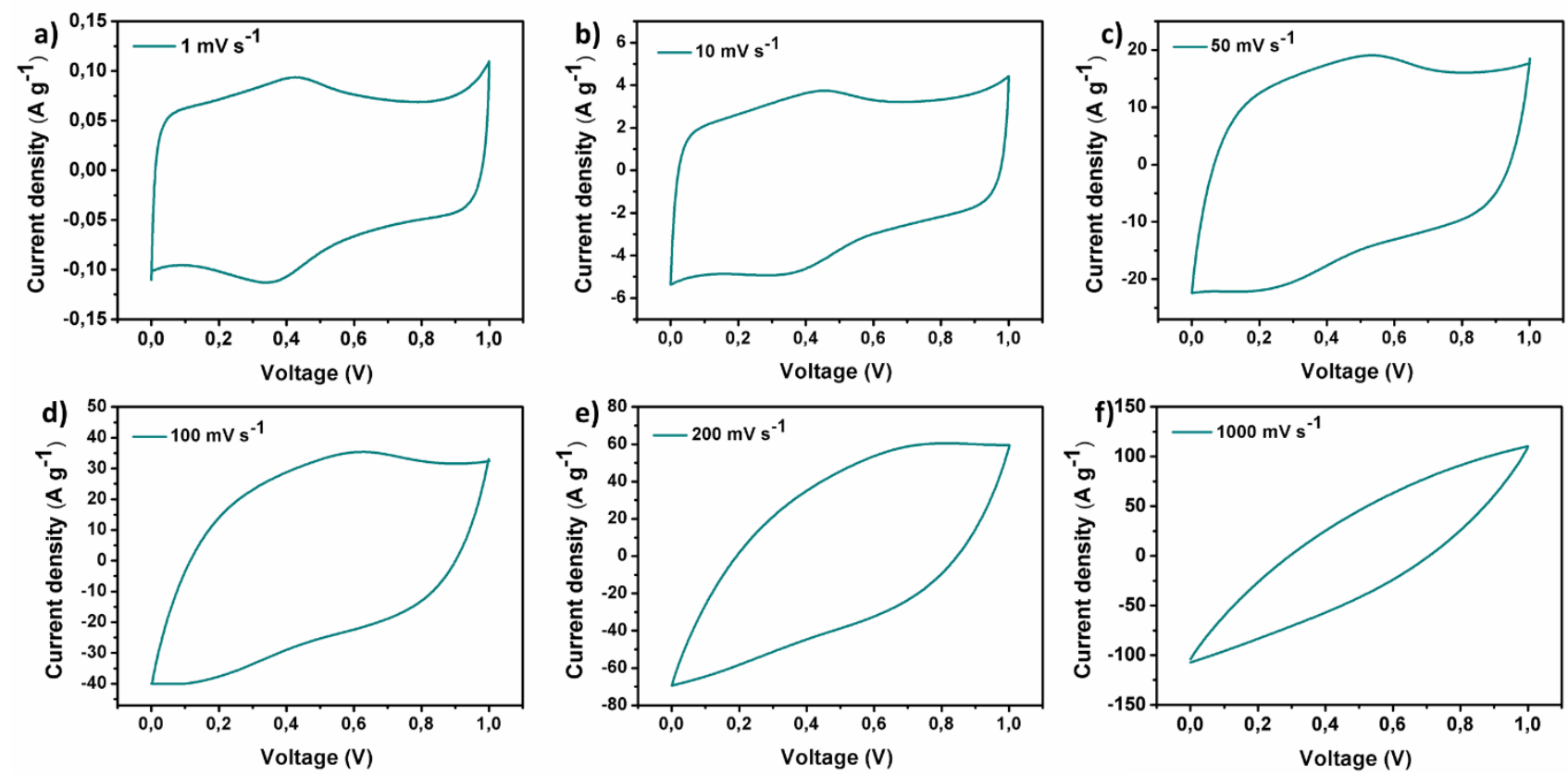

Fig. 4 Cyclic voltammetry curves of rGO-POSS electrode at different scan rates (1-1000 $\left.\mathrm{mV} \mathrm{s}^{-1}\right)$. 

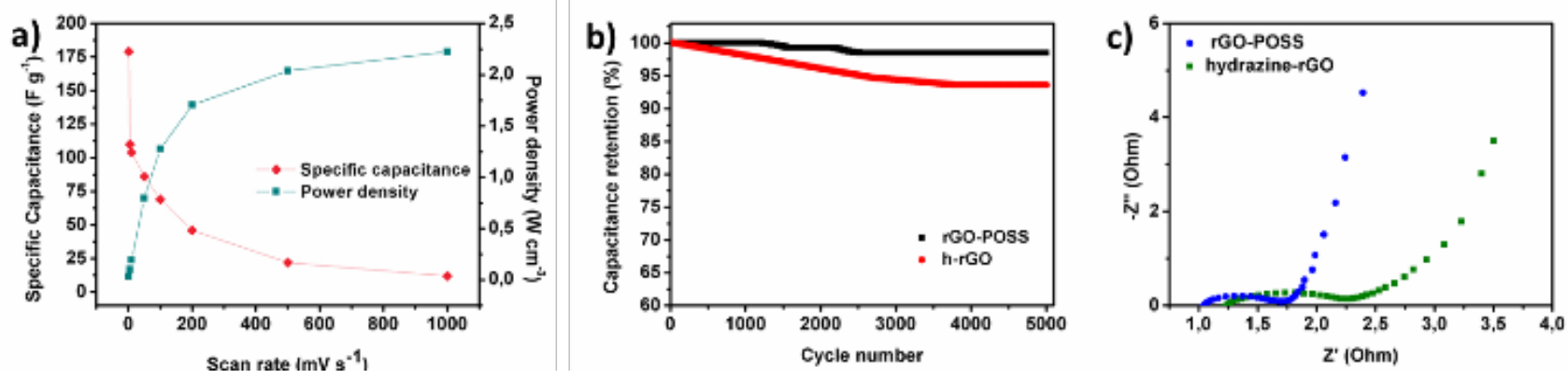

Fig. 5 a) The dependence of specific capacitance and power density at various scan rates values for rGO-POSS. b) Cyclic stability of electrodes at $100 \mathrm{mV} \mathrm{s}^{-1}$ for rGO-POSS and h-rGO c) comparison of Nyquist plots for rGO-POSS and hydrazine reduced graphene oxide.

which might be provided by presence of heteroatoms (such as nitrogen, oxygen and silicon). ${ }^{56,57}$ With the scan rate increase, an obvious drop in specific capacitance is observed, e.g. $86 \mathrm{~F} \mathrm{~g}$ 1 at $50 \mathrm{mv} \mathrm{s}^{-1}$, sustaining good electrochemical performance (Fig. 5a). Further experiments show significant drop in specific capacitance comparable to pristine rGO electrode. Notably, the prepared electrode exhibited also good areal capacitance of 350 $\mathrm{mF} \mathrm{cm} \mathrm{cm}^{-2}$ and volumetric capacitance reaching $115 \mathrm{~F} \mathrm{~cm}^{-3}$.

The prepared electrode displayed power density of $2.25 \mathrm{~W} \mathrm{~cm}^{-}$ 3 at operating voltage of $1 \mathrm{~V} \mathrm{~s}^{-1}$ (Fig. 5a). Notably, the prepared electrode revealed excellent cyclability: its electrochemical capacitance remains at level over $98 \%$ of initial capacitance after 5000 cycles while tested at scan rate of $100 \mathrm{mV} \mathrm{s}^{-1}$ in aqueous media which is superior while compared with reference rGO material which drops to $95 \%$ at the same conditions (Fig. 5b, Fig. S9). Galvanostatic charge-discharge curves at the current density of $1 \mathrm{~A} \mathrm{~g}^{-1}$ reveal significant difference in the cycle time for rGO-POSS (290 s) when compared to reference $\mathrm{rGO}(190 \mathrm{~s})$. Electrochemical impedance spectroscopy (EIS) was employed to gain kinetic information of the electrode materials wherein the data was obtained in the form of Nyquist plot where the real part of impedance was plotted against the imaginary part of the impedance. The Warburg resistance (the slope of $45^{\circ}$ region of the plots) for rGO-POSS electrode was estimated as $1.75 \mathrm{ohm}$, indicating fast charge transfer during the energy storage process and good conductivity and better ion transfer between the electrolyteelectrode than hydrazine reduced graphene oxide (Fig. 5c). A volumetric energy density $(E)$ constitutes an important parameter, especially for real application in electric vehicles and mobile devices. Our electrodes exhibited energy density as high as $41.4 \mathrm{mWh} \mathrm{cm}^{-3}$.

\section{Experimental}

\subsection{Materials}

Graphene oxide (GO) $4 \mathrm{mg} \mathrm{mL}-1$ aqueous dispersion was acquired from Graphenea. Hydrazine monohydrate and absolute ethanol (Sigma Aldrich) were used as received without purification. OctaAmmonium POSS (AM0285) was purchased from Hybrid Plastics Inc. Carbon Black Super P (H30253) was acquired from Alfa Aesar. All the solutions were prepared using Milli-Q water.
3.2 Preparation of rGO-POSS hybrid. A batch of rGO-POSS is prepared as follows: a mixture of ethanol $(100 \mathrm{ml})$ and GO (100 $\mathrm{ml}, 4 \mathrm{mg} \mathrm{mL}^{-1}$ ) was sonicated for $15 \mathrm{~min}$ and added to the solution of POSS (1 g in $200 \mathrm{~mL}$ of DI water) The mixture was rigorously stirred overnight under reflux. After 24 hours precipitate was filtrated, rinsed several times with water and ethanol then obtained GO-POSS was dried under vacuum. 570 $\mathrm{mg}$ of GO-POSS was dispersed in water and $570 \mu \mathrm{L}$ of hydrazine was added and stirred for another 6 hours. The precipitate was then filtrated and rinsed with a large amount of water and ethanol. The resulting black powder was then freeze-dried for $24 \mathrm{~h}$ under vacuum.

\subsection{Characterization techniques}

FT-IR spectra were studied within the mid-IR range (400-4000 $\mathrm{cm}^{-1}$ ) by using a Perkin Elmer Spectrometer (Spectrum Two) equipped with ATR Diamond. X-ray photoelectron spectroscopy (XPS) analyses were carried out on a Thermo Scientific KAlpha $\mathrm{X}$-ray photoelectron spectrometer with a basic chamber pressure of $\sim 10^{-9} \mathrm{mbar}$ and an $\mathrm{Al}$ anode as the X-ray source ( $\mathrm{X}$ ray radiation of $1486 \mathrm{eV}$ ). X-ray powder diffraction (XRD) experiments were conducted on powder specimens using Bruker ASX D8 Advanced equipped with $\mathrm{Cu}$ anode with $\mathrm{K} \alpha$ radiation $(\lambda=1.5418 \AA$ ). Diffraction patterns were collected at room temperature in the scattered angular range between $6^{\circ}$ and $40^{\circ}$ with an angular resolution of $0.02^{\circ}$ per step and a typical counting time 4 of $10 \mathrm{~s}$ per step. The specific surface area was measured by using a Micromeritics ASAP 2050 surface area and porosity analyzer. Prior to the BET measurements, the samples were outgassed for 12 hours at $100{ }^{\circ} \mathrm{C}$. Adsorption isotherms were calculated for nitrogen adsorption at $77 \mathrm{~K}$ and pressures up to 1 bar. Scanning Electron Microscopy (SEM): characterization is carried out by means of a FEI Quanta 250 FEG instrument with energy-dispersive X-ray (EDX) analyses. High Resolution Transmission Electron Microscopy (HR-TEM) was performed with Hitachi HT7700.

\subsection{Electrochemical measurements}

The working electrode (disc with diameter of $0.7 \mathrm{~cm}$ and thickness of $30 \mu \mathrm{m}$ ) was prepared by vacuum filtration of rGOPOSS dispersed in ethanol and carbon black (as conducting additive, $10 \mathrm{wt} \%$ ratio of the total mass of the film). After drying, 
a free-standing pastille was deposited on Au-covered polyethylene terephthalate (PET) substrate by pressing under a pressure of $10 \mathrm{MPa}$ for 24 hours (Fig. S5). A platinum wire was employed as the counter electrode and $\mathrm{Ag} / \mathrm{AgCl}$ electrode in $\mathrm{KCl}$ was used as the reference electrode. $1 \mathrm{M} \mathrm{H}_{2} \mathrm{SO}_{4}$ aqueous solution was used as electrolyte for $\mathrm{CV}$ measurements. The $\mathrm{CV}$ curves were performed under a potential window from $0 \mathrm{~V}$ to 1 $\mathrm{V}$ at different scan rates in the range from 1 to $1000 \mathrm{mV} \mathrm{s}^{-1}$. The capacitance was calculated from the CV curves using the equation $1^{58}$ :

$$
C=\frac{1}{m \times \Delta v \times s} \int_{v_{0}}^{v} i d v+\int_{v}^{v_{0}} i d v(1)
$$

where $C$ is the capacitance $\left(\mathrm{F} \mathrm{g}^{-1}\right), m$ is the mass loading of active material, $\Delta v$ is the voltage window in the measurement, $s$ is the scan speed for each CV measurement. The energy density (equation 2) and power density (equation 3 ) were calculated as given ${ }^{59}$ :

$$
E=\frac{1}{2} \times C \times \frac{\Delta V}{3600}(2) \quad P=\frac{E}{\Delta t} \times 3600
$$

Where $\mathrm{E}$ is the energy density $\left(\mathrm{Wh} \mathrm{cm}^{-3}\right), \mathrm{C}$ is the volumetric capacitance, $\Delta \mathrm{V}$ is the discharge voltage range, $\mathrm{P}$ is the power density (in $\mathrm{W} \mathrm{cm}^{-3}$ ), $\mathrm{E}$ is the volumetric energy and $\Delta \mathrm{t}$ is the discharge time. CV, Galvanostatic charge/discharge and electrochemical impedance spectroscopy was measured with EC-LAB VMP3 (BioLogic Science Instruments).

\section{Conclusions}

In conclusion, we have demonstrated a facile approach of covalent functionalization of graphene oxide with silsesquioxane (POSS) followed by chemical reduction and exploited the hybrid structure as electrode for supercapacitors. Due to introduction of POSS cages and optimization of oxygen content, the final material exhibited three-dimensional porous structure which was fully characterized in terms of morphology, chemical composition and electrochemical behaviour. The prepared electrode exhibited high specific, areal and volumetric capacitance $\left(171 \mathrm{~F} \mathrm{~g} \mathrm{~g}^{-1}, 350 \mathrm{mF} \mathrm{cm} \mathrm{cm}^{-2}\right.$ and $115 \mathrm{~F} \mathrm{~cm}^{-3}$, respectively). The introduction of POSS molecules provided optimal pores allowing efficient electrolyte penetration while electrochemical processes resulting in excellent performance over wide range of scan rates. Moreover, the electrode revealed excellent durability and cyclability maintaining $>98 \%$ capacitance retention after 5000 cycles showing superior electrochemical performance when compared with rGO. This work enriches the current family of modern molecularly engineered graphene-based energy storage materials. Such approach enables the tuning of a variety of physico-chemical properties of the hybrid system towards the generation of high performing multifunctional electrode materials exhibiting enhanced stability.

\section{Conflicts of interest}

There are no conflicts to declare

\section{Acknowledgements}

This work was financially supported by the National Science Center (Grant No. 2019/35/B/ST5/01568, and Grant No. 2019/33/N/ST5/00052), Grant no. POWR.03.02.00-00-I026/16 co-financed by the European Union through the European Social Fund under the Operational Program Knowledge Education Development, as well as the EC - Graphene Flagship Core 3 project (GA-881603), the Agence Nationale de la Recherche through the Labex project CSC (ANR-10-LABX-0026 CSC) within the Investissement d'Avenir program (ANR-10-120 IDEX-0002-02) and the International Center for Frontier Research in Chemistry (icFRC). S.W. acknowledges the support from the Foundation for Polish Science (FNP) in the form of scholarship.

\section{Notes and references}

₹ Footnotes relating to the main text should appear here. These might include comments relevant to but not central to the matter under discussion, limited experimental and spectral data, and crystallographic data.

1. F. X. Wang, X. W. Wu, X. H. Yuan, Z. C. Liu, Y. Zhang, L. J. Fu, Y. S. Zhu, Q. M. Zhou, Y. P. Wu and W. Huang, Chemical Society Reviews, 2017, 46, 6816-6854.

2. N. Choudhary, C. Li, J. Moore, N. Nagaiah, L. Zhai, Y. Jung and J. Thomas, Adv. Mater., 2017, 29, 30.

3. Z. Liu, H. Zhang, M. Eredia, H. Qiu, W. Baaziz, O. Ersen, A. Ciesielski, M. Bonn, H. I. Wang and P. Samorì, ACS Nano, 2019, 13, 9431-9441.

$4 . \quad$ Z. P. Song and H. S. Zhou, Energy \& Environmental Science, 2013, 6, 2280-2301.

5. Z. N. Yu, L. Tetard, L. Zhai and J. Thomas, Energy \& Environmental Science, 2015, 8, 702-730.

6. C. Zhong, Y. D. Deng, W. B. Hu, J. L. Qiao, L. Zhang and J. J. Zhang, Chemical Society Reviews, 2015, 44, 7484-7539.

7. Z. B. Lei, L. Lu and X. S. Zhao, Energy \& Environmental Science, 2012, 5, 6391-6399.

8. H. Ren, H. Tian, C. L. Gardner, T.-L. Ren and J. Chae, Nanoscale, 2016, 8, 3539-3547.

9. J. Y. Chen, P. Xie and Z. P. Zhang, Chemical Engineering Journal, 2019, 361, 615-624.

10. F. Wang, Z. Hu, L. Mao and J. Mao, Journal of Power Sources, 2020, 450, 227692.

11. C. Moreno, M. Vilas-Varela, B. Kretz, A. Garcia-Lekue, M. V. Costache, M. Paradinas, M. Panighel, G. Ceballos, S. O. Valenzuela, D. Pena and A. Mugarza, Science, 2018, 360, 199-203.

12. H. J. Jiang, Small, 2011, 7, 2413-2427.

13. A. Ciesielski and P. Samori, Chemical Society Reviews, 2014, 43, 381-398.

14. V. Eswaraiah, S. S. J. Aravind and S. Ramaprabhu, J. Mater. Chem., 2011, 21, 6800-6803.

15. D. R. Dreyer, S. Park, C. W. Bielawski and R. S. Ruoff, Chemical Society Reviews, 2010, 39, 228-240.

16. Y. Zhu, S. Murali, W. Cai, X. Li, J. W. Suk, J. R. Potts and R. S. Ruoff, 2010, 22, 3906-3924.

$17 . \quad$ S. H. Dave, C. Gong, A. W. Robertson, J. H. Warner and J. C. Grossman, ACS Nano, 2016, 10, 7515-7522. 
18

C. Punckt, F. Muckel, S. Wolff, I. A. Aksay, C. A. Chavarin, G. Bacher and W. Mertin, Applied Physics Letters, 2013, 102, 023114.

19. S. J. Rowley-Neale, E. P. Randviir, A. S. Abo Dena and C. E. Banks, Applied Materials Today, 2018, 10, 218-226.

20. C. K. Chua and M. Pumera, Chemical Society Reviews, 2014, 43, 291-312.

21. S. Eigler, S. Grimm, M. Enzelberger-Heim, P. Müller and A. Hirsch, Chemical Communications, 2013, 49, 7391-7393.

22. M. J. Fernández-Merino, L. Guardia, J. I. Paredes, S. VillarRodil, P. Solís-Fernández, A. Martínez-Alonso and J. M. D. Tascón, The Journal of Physical Chemistry C, 2010, 114, 6426-6432.

23. S. Pei and H.-M. Cheng, Carbon, 2012, 50, 3210-3228.

24. X. Gao, J. Jang and S. Nagase, The Journal of Physical Chemistry C, 2010, 114, 832-842.

25. D. Voiry, J. Yang, J. Kupferberg, R. Fullon, C. Lee, H. Y. Jeong, H. S. Shin and M. Chhowalla, 2016, 353, 1413-1416.

26. L. G. Guex, B. Sacchi, K. F. Peuvot, R. L. Andersson, A. M. Pourrahimi, V. Ström, S. Farris and R. T. Olsson, Nanoscale, 2017, 9, 9562-9571.

27. S. Park, J. An, J. R. Potts, A. Velamakanni, S. Murali and R. S. Ruoff, Carbon, 2011, 49, 3019-3023.

28. P. K. Jha, S. K. Singh, V. Kumar, S. Rana, S. Kurungot and N. Ballav, Chem, 2017, 3, 846-860.

29. C. Zhao, K. Shu, C. Wang, S. Gambhir and G. G. Wallace, Electrochimica Acta, 2015, 172, 12-19.

30. H. J. Kim, S.-Y. Lee, L. H. Sinh, C. S. Yeo, Y. R. Son, K. R. Cho, Y. Song, S. Ju, M. K. Shin, S.-J. Park and S. Park, Journal of Power Sources, 2017, 346, 113-119.

31. H. H. Shi, S. Jang, A. Reza-Ugalde and H. E. Naguib, ACS Applied Energy Materials, 2020, 3, 987-997.

32. Z. Lei, N. Christov and X. S. Zhao, Energy \& Environmental Science, 2011, 4, 1866-1873.

33. V. H. Luan, H. N. Tien, L. T. Hoa, N. T. M. Hien, E.-S. Oh, J. Chung, E. J. Kim, W. M. Choi, B.-S. Kong and S. H. Hur, Journal of Materials Chemistry A, 2013, 1, 208-211.

34. H. Kang, C. Zhang, Y. Xu, W. Zhang, J. Jiao, Z. Li, L. Zhu and X. Liu, RSC Advances, 2020, 10, 1507-1513.

35. K. Tanaka and Y. Chujo, Journal of Materials Chemistry, 2012, 22, 1733-1746.

36. S. K. Yadav, S. S. Mahapatra, H. J. Yoo and J. W. Cho, Nanoscale Research Letters, 2011, 6, 122.

37. Y. Xue, Y. Liu, F. Lu, J. Qu, H. Chen and L. Dai, The Journal of Physical Chemistry Letters, 2012, 3, 1607-1612.

38. D. Pakulski, W. Czepa, S. Witomska, A. Aliprandi, P. Pawluć, V. Patroniak, A. Ciesielski and P. Samorì, Journal of Materials Chemistry A, 2018, 6, 9384-9390.

39. P. M. Sudeep, T. N. Narayanan, A. Ganesan, M. M. Shaijumon, H. Yang, S. Ozden, P. K. Patra, M. Pasquali, R. Vajtai, S. Ganguli, A. K. Roy, M. R. Anantharaman and P. M. Ajayan, ACS Nano, 2013, 7, 7034-7040.

40. Y. Qin, J. Yuan, J. Li, D. Chen, Y. Kong, F. Chu, Y. Tao and M. Liu, Advanced Materials, 2015, 27, 5171-5175.

41. T. Kolev, M. Spiteller and B. Koleva, Amino acids, 2010, 38, 45-50.

42. D. M. El-Gendy, N. A. A. Ghany, E. E. F. El Sherbini and N. K. Allam, Scientific Reports, 2017, 7, 43104.

43. H.-L. Ma, H.-B. Zhang, Q.-H. Hu, W.-J. Li, Z.-G. Jiang, Z.-Z. Yu and A. Dasari, ACS Applied Materials \& Interfaces, 2012, 4, 1948-1953.
44. 45.

.

46.

47. Wanke, O. Bianchi and M. R. F. Soares, Journal of NonCrystalline Solids, 2015, 428, 82-89.

48. S. Chen, J. Zhu, X. Wu, Q. Han and X. Wang, ACS Nano, 2010, 4, 2822-2830.

49. S. Witomska, Z. Liu, W. Czepa, A. Aliprandi, D. Pakulski, P. Pawluć, A. Ciesielski and P. Samorì, Journal of the American Chemical Society, 2019, 141, 482-487.

50. A. Strąkowska;, S. Członka; and K. Strzelec, Polymers (Basel), 2019, 11, 1092.

51. J. H. Bae, J.-H. Han and T. D. Chung, Physical Chemistry Chemical Physics, 2012, 14, 448-463.

52. B. Moyo, D. Momodu, O. Fasakin, A. Bello, J. Dangbegnon and N. Manyala, Journal of Materials Science, 2018, 53, 5229-5241.

53. H. Lu, K. Kim, Y. Kwon, X. Sun, R. Ryoo and X. S. Zhao, Journal of Materials Chemistry A, 2018, 6, 10388-10394.

54. A. Sumboja, C. Y. Foo, X. Wang and P. S. Lee, Advanced Materials, 2013, 25, 2809-2815.

55. Z. Lei, L. Lu and X. S. Zhao, Energy \& Environmental Science, 2012, 5, 6391-6399.

56. C. Romanitan, P. Varasteanu, I. Mihalache, D. Culita, S. Somacescu, R. Pascu, E. Tanasa, S. A. V. Eremia, A. Boldeiu, M. Simion, A. Radoi and M. Kusko, Scientific Reports, 2018, 8, 9654.

57. Y. J. Oh, J. J. Yoo, Y. I. Kim, J. K. Yoon, H. N. Yoon, J.-H. Kim and S. B. Park, Electrochimica Acta, 2014, 116, 118-128.

58. M. D. Stoller, S. Park, Y. Zhu, J. An and R. S. Ruoff, Nano Lett., 2008, 8, 3498-3502.

59. Z. S. Wu, K. Parvez, X. Feng and K. Müllen, Nature Communications, 2013, 4, 2487. 